\title{
Target Occupancy Study and Whole-Body Dosimetry with a MAGL PET Ligand 11C-PF-06809247 in non- human Primates
}

Ryosuke Arakawa ( $\nabla$ ryosuke.arakawa@ki.se )

Karolinska Institutet https://orcid.org/0000-0001-5569-1361

Akihiro Takano

Karolinska Institutet

Sangram Nag

Karolinska Institutet

Zhisheng Jia

Karolinska Institutet

Nahid Amini

Karolinska Institutet

Kevin P Maresca

Pfizer Inc

Lei Zhang

Pfizer Inc

Edmund J Keliher

Pfizer Inc

Christopher R Butler

Pfizer Inc

Justin R Piro

Pfizer Inc

Tarek A Samad

Pfizer Inc

Deborah Smith

Pfizer Inc

Deane Nason

Pfizer Inc

Steve O'Neil

Pfizer Inc

Patrick Trapa

Pfizer Inc

Kari R Fonseca 
Pfizer Inc

John Litchfield

Pfizer Inc

Timothy McCarthy

Pfizer Inc

\section{Richard E Carson}

Yale University

Christer Halldin

Karolinska Institutet

\section{Research Article}

Keywords: MAGL, non-human primate, occupancy, PET, radiation dose

Posted Date: September 21st, 2021

DOl: https://doi.org/10.21203/rs.3.rs-510615/v2

License: (9) This work is licensed under a Creative Commons Attribution 4.0 International License. Read Full License

Version of Record: A version of this preprint was published at EJNMMI Research on March 4th, 2022. See the published version at https://doi.org/10.1186/s13550-022-00882-2. 


\section{Abstract}

\section{Background}

Monoacylglycerol lipase (MAGL) is a key serine hydrolase which terminates endocannabinoid signaling and regulates arachidonic acid driven inflammatory responses within the central nervous system (CNS). To develop [ $\left.{ }^{11} \mathrm{C}\right] \mathrm{PF}-06809247$ into a clinically usable positron emission tomography (PET) radioligand, we assessed the brain target occupancy of a MAGL inhibitor using non-human primate (NHP). Additionally, we measured the whole-body distribution of $\left[{ }^{11} \mathrm{C}\right] \mathrm{PF}-06809247$ in NHP and estimated human effective radiation doses.

\section{Methods}

Seven cynomolgus monkeys were enrolled for brain PET measurements. Two PET measurements were performed in each NHP: one baseline and one pretreatment condition with intravenous administration of PF-06818883, a selective MAGL inhibitor, (total of seven doses between 0.01-1.27 mg/kg). Kinetic parameters $\mathrm{K}_{1}, \mathrm{k}_{2}$ and $\mathrm{k}_{3}$ were estimated by an irreversible two tissue compartment (2TC) model using metabolite corrected plasma radioactivity as the input function. $\mathrm{K}_{\mathrm{i}}$ by $2 \mathrm{TC}$ and Patlak analysis were calculated. The target occupancy was calculated using $\mathrm{K}_{\mathrm{i}}$ at baseline and pretreatment conditions. Two cynomolgus monkeys were enrolled for whole-body PET measurements. Estimates of the absorbed radiation dose in humans were calculated with OLINDA/EXM 1.1 using the adult male reference model.

Results

Radioactivity was decreased in all brain regions following pretreatment with PF-06818883. Occupancy was measured as $25.4 \%-100.5 \%$ in a dose dependent manner. Whole-body PET showed high uptake values in the liver, small intestine, kidney, and brain. The effective dose was calculated as $4.3 \mu \mathrm{Sv} / \mathrm{MBq}$.

Conclusions

$\left[{ }^{11} \mathrm{C}\right] \mathrm{PF}-06809247$ is a promising PET ligand for further MAGL studies in human brain.

\section{Background}

Monoacylglycerol lipase (MAGL) is a serine hydrolase highly expressed throughout the brain and is responsible for converting 2-arachidonylglycerol (2-AG) to arachidonic acid (AA) [1, 2]. As such, the MAGL hydrolytic activity has an important role regulating endocannabinoid signaling as well as inflammatory responses. Inhibition of MAGL has been proposed as a therapeutic strategy for a variety of central nervous system (CNS) injuries and disorders including status epilepticus [3], dysfunction of blood brain barrier permeability [4] and neurodegenerative diseases such as Alzheimer's disease, Parkinson's disease and multiple sclerosis, as well as neuropsychiatric disorders, etc. [5-7]. 
Positron emission tomography (PET) is a useful modality for evaluating the proof of concept of novel drugs. Favorable PET radioligands require suitable properties such as high brain accumulation and high specificity for the target protein. Rationale design of a glycol-derived MAGL PET radioligand was accomplished as PF-06809247, which was successfully radio-labelled by $\left[{ }^{11} \mathrm{C}\right]$ methylation $\left(\left[{ }^{11} \mathrm{C}\right] \mathrm{PF}-\right.$ 06809247) in high molar activity [8]. The preliminary evaluation showed high uptake in non-human primate (NHP) brain, and clear blocking effect by a MAGL inhibitor.

To further develop $\left[{ }^{11} \mathrm{C}\right] \mathrm{PF}-06809247$ into a clinically usable PET radioligand, we assessed the relationship between MAGL target occupancy in the NHP brain and the plasma exposure for a MAGL inhibitor. Additionally, we measured the whole-body distribution of $\left[{ }^{11} \mathrm{C}\right] \mathrm{PF}-06809247$ in NHP and estimated the human effective radiation doses based on the NHP data.

\section{Methods}

The study was approved by the Animal Ethics Committee of the Swedish Animal Welfare Agency (N185/14) and was performed according to "Guidelines for planning, conducting and documenting experimental research" (Dnr 4820/06-600) of Karolinska Institutet. The NHPs were housed in the Astrid Fagraeus Laboratory of the Swedish Institute for Infectious Disease Control, Solna, Sweden.

\section{Radioligand synthesis}

$\left[{ }^{11}\right.$ C]PF-06809247 was synthesized as reported previously [8] (Supplemental text).

\section{Brain PET measurements}

Seven cynomolgus monkeys (two females and five males, body weight $5850-8000 \mathrm{~g}$ ) were used. Anesthesia was induced by intramuscular injection of ketamine hydrochloride $(10 \mathrm{mg} / \mathrm{kg})$ at Astrid Fagraeus Laboratory and maintained by the administration of a mixture of isoflurane (1.5-2.0\%), oxygen and medical air through endotracheal intubation. The subjects' cranium was immobilized with a fixation device. Body temperature was maintained by a Bair Hugger model 505 warming unit (Arizant Healthcare, $\mathrm{MN}$ ) and monitored by an esophageal thermometer. Heart rate, blood pressure, respiratory rate and oxygen saturation were continuously monitored throughout the experiments. Fluid balance was maintained by continuous infusion of saline.

PET measurements were conducted using a High Resolution Research Tomograph (HRRT) (Siemens Molecular Imaging). A transmission scan of 6 min using a single ${ }^{137} \mathrm{Cs}$ source was performed before the $\left[{ }^{11} \mathrm{C}\right] \mathrm{PF}-06809247$ injection. List mode data were acquired continuously for $123 \mathrm{~min}$ (first two NHPs) or 63 min (remaining five NHPs) immediately after intravenous injection of the radioligand. Images were reconstructed with a series of 34 frames $(20 \mathrm{sec} \times 9,1 \mathrm{~min} \times 3,3 \mathrm{~min} \times 5$, and $6 \mathrm{~min} \times 17)$ for $123 \mathrm{~min}$ data or 33 frames $(10 \mathrm{sec} \times 9,15 \mathrm{sec} \times 2,20 \mathrm{sec} \times 3,30 \mathrm{sec} \times 4,1 \mathrm{~min} \times 4,3 \mathrm{~min} \times 4$, and $6 \mathrm{~min} \times 7)$ for $63 \mathrm{~min}$ data. The ordinary Poisson-3D-ordered subset expectation maximization (OP-3D-OSEM) algorithm was 
applied with 10 iterations and 16 subsets including modeling of the point spread function (PSF) [9]. Two PET measurements per NHP were performed in one day: one baseline and one following pretreatment.

\section{MRI Measurements}

T1-weighted magnetic resonance image (MRI) of the individual NHP brains had been obtained using a 1.5T GE Healthcare Signa system (GE, Milwaukee, Wis, USA). A spoiled gradient recalled (SPGR) sequence had been acquired in the coronal plane with the following parameters: $T R=21 \mathrm{~ms} ; \mathrm{TE}=4 \mathrm{~ms}$; flip angle $=35^{\circ}$; Slice thickness $=1.0 \mathrm{~mm}$; FOV $=12.8 \mathrm{~cm}$; NEX $=2$; voxel size $=0.5 \times 0.5 \times 1 \mathrm{~mm}^{3}$.

\section{Arterial blood sampling}

An automated blood-sampling system (ABSS) was used to continuously measure the radioactivity for the first $3 \mathrm{~min}$ after the radioligand injection. Blood sampling was performed manually for the measurement of radiometabolism and radioactivity at 2, 4, 10, 20, 30, 60 (also 90 and 120 for first two NHPs) min after the injection.

\section{Radiometabolite analysis}

A reversed-phase radio-HPLC method was used to determine the amount of unchanged [ $\left.{ }^{11} \mathrm{C}\right] \mathrm{PF}-06809247$ and its radioactive metabolites in NHP plasma [10]. The plasma obtained after centrifugation of blood at $2000 \mathrm{~g}$ for 2-4 min was mixed with acetonitrile. The mixture was then centrifuged at $2000 \mathrm{~g}$ for $2-4$ min and the extract was injected into a HPLC system coupled to an on-line radioactivity detector. The radioHPLC system used consisted of an interface module (D-7000; Hitachi: Tokyo, Japan), a L-7100 pump (Hitachi), an injector (model 7125, with a 5.0-mL loop; Rheodyne: Cotati, USA), and an ultraviolet absorption detector (L-7400, $254 \mathrm{~nm}$; Hitachi) in series with a 150TR; Packard (housed in a shield of 50 $\mathrm{mm}$ thick lead) equipped with a $550 \mu \mathrm{L}$ flow cell. Chromatographic separation was achieved on a XBridge C18 column, (50 mm × $10 \mathrm{~mm}$ I.D., $2.5 \mu \mathrm{m}+10 \mathrm{~mm} \times 10 \mathrm{~mm}$ I.D., $5 \mu \mathrm{m}$; Waters: New England, USA) by gradient elution. Acetonitrile $(A)$ and $20 \mathrm{mM}$ ammonium phosphate $(\mathrm{pH} 7)(B)$ were used as the mobile phase at $6.0 \mathrm{~mL} / \mathrm{min}$, according to the following program: $0-3.5 \mathrm{~min},(A / B) 20: 80 \rightarrow 55: 45 \mathrm{v} / \mathrm{v} ; 3.5-4.0$ $\min ,(A / B) 55: 45 \mathrm{v} / \mathrm{v} ; 4.0-4.1 \mathrm{~min},(\mathrm{~A} / \mathrm{B})$ 55:45 $\rightarrow$ 20:80 v/v; $4.1-5.0 \mathrm{~min},(\mathrm{~A} / \mathrm{B})$ 20:80 v/v. Peaks for radioactive compounds eluting from the column were integrated and their areas were expressed as a percentage of the sum of the areas of all detected radioactive compounds (decay-corrected to the time of injection on the HPLC).

\section{Protein binding}

A blood sample was taken at 3 min before injection for measurement of protein binding and determination of free fraction of $\left[{ }^{11} \mathrm{C}\right] \mathrm{PF}-06809247$ in the plasma. The free fraction, $f_{\mathrm{p}}$, of $\left[{ }^{11} \mathrm{C}\right] \mathrm{PF}-$ 06809247 in plasma was estimated using an ultrafiltration method [11]. Plasma (400 $\mu \mathrm{L})$ or phosphate buffered saline solution $(400 \mu \mathrm{L})$ as a control were mixed with [ $\left.{ }^{11} \mathrm{C}\right] \mathrm{PF}-06809247(40 \mu \mathrm{L}, \sim 1 \mathrm{MBq})$ and incubated at room temperature for 10 minutes. After the incubation, $200 \mu \mathrm{L}$ portions of the incubation mixtures were pipetted into ultrafiltration tubes (Centrifree YM-30, molecular weight cutoff, 30,000; Millipore: Billerica, USA) and centrifuged at $1500 \mathrm{~g}$ for $15 \mathrm{~min}$. Equal aliquots $(20 \mu \mathrm{L})$ of the ultrafiltrate 
$\left(C_{\text {free }}\right)$ and of the plasma $\left(C_{\text {total }}\right)$ were counted for their radioactivity with a 2480 Wizard2 Automatic Gamma Counter (Perkin Elmer: Massachusetts, USA). Each determination was performed in duplicate. The free fraction was then calculated as $f_{\mathrm{p}}=C_{\text {free }} / C_{\text {total }}$, and the results were corrected for the membrane binding measured with the control samples.

\section{Drug administration}

PF-06818883 was administered intravenously as a bolus infusion ( 15 seconds, volume; $0.5 \mathrm{~mL} / \mathrm{kg}$ ) of seven different doses $(0.01-1.27 \mathrm{mg} / \mathrm{kg}$ ) approximately 1 hour before PET scanning [12] (Table 1). PF06818883 was formulated by dissolving in PBS with a final $\mathrm{pH}$ of 7.5. A single dose was administered to four NHPs while three NHPs received two different doses.

Table 1

Dose of PF-06818883, plasma concentration of PF-06807893, and MAGL occupancy

\begin{tabular}{|lllll|}
\hline & $\begin{array}{l}\text { Dose } \\
(\mathbf{m g} / \mathbf{k g})\end{array}$ & $\begin{array}{l}\text { Conc } \\
(\mathbf{n g} / \mathbf{m L})\end{array}$ & $\mathbf{2 T C} \mathbf{K}_{\mathbf{i}}$ & Patlak slope \\
\hline NHP1 & 1.27 & 338.5 & $94.1 \%$ & $99.4 \%$ \\
\hline NHP2 & 1.27 & 370.0 & $90.8 \%$ & $100.5 \%$ \\
\hline NHP3 & 0.03 & 0.7 & $32.0 \%$ & $34.8 \%$ \\
\hline NHP4 & 0.14 & 10.3 & $91.5 \%$ & $99.3 \%$ \\
\hline NHP5 & 0.03 & 2.2 & $59.9 \%$ & $60.4 \%$ \\
\hline & 0.42 & 45.6 & $94.1 \%$ & $98.8 \%$ \\
\hline NHP6 & 0.07 & 10.3 & $86.3 \%$ & $90.9 \%$ \\
\hline NHP7 & 0.01 & - & $22.8 \%$ & $25.4 \%$ \\
\hline NHP; non-huma primate, Conc; concentration of plasma, 2TC; two-tissue compartment model & $91.1 \%$ & $96.4 \%$ \\
\hline
\end{tabular}

Measurement of plasma concentration of PF-06807893

Venous blood samples ( $1 \mathrm{~mL}$ each) were taken at -63,-30,-1, 30, 60 (also 90 and 120 for first two NHPs) min after the radioligand injection of PET measurements to measure the plasma concentration of PF06807893. PF-06818883 is a pro-drug and it converts to PF-06807893. The blood samples were collected in a plasma-tube containing K2 EDTA as an anticoagulant. The plasma samples were harvested by centrifuging the blood sample at a speed of $1200 \times \mathrm{g}$ for $10 \mathrm{~min}$ at $4^{\circ} \mathrm{C}$. The harvested plasma samples were immediately stored in $-80^{\circ} \mathrm{C}$ freezer. The plasma concentration of PF- 06807893 was measured at an analysis laboratory (Unilabs York Bioanalytical Solutions, UK). 


\section{Brain image analysis}

The regions of interest (ROIs) were delineated manually on MRI images of each NHP for the whole brain, cerebellum, caudate, putamen, thalamus, frontal cortex, temporal cortex, and hippocampus. The summed PET images of the whole duration were co-registered to the MRI image of the individual NHP. After applying the co-registration parameters to the dynamic PET data, the time-activity curves of brain regions were generated for each PET measurement.

\section{Kinetic model analysis}

Kinetic parameters as $\mathrm{K}_{1}, \mathrm{k}_{2}$ and $\mathrm{k}_{3}$ were estimated by two tissue compartment (2TC) using metabolite corrected plasma radioactivity as the input function [13]. $\mathrm{k}_{4}$ was set as 0 according to the irreversible binding of $\left[{ }^{11} \mathrm{C}\right] \mathrm{PF}-06809247$. As the main outcome measures, $\mathrm{K}_{\mathrm{i}}$ defined as $\left(\mathrm{K}_{1} \times \mathrm{k}_{3}\right) /\left(\mathrm{k}_{2}+\mathrm{k}_{3}\right)$ and Patlak slope were calculated [14]. Due to low reliable data for parent fraction of [ $\left.{ }^{11} \mathrm{C}\right] \mathrm{PF}-06809247$ at later phase, only up to 30 min data was used for the quantification. The relation between $K_{i}$ by $2 T C$ and Patlak slope was evaluated by linear correlation.

\section{Estimation of the target occupancy}

The target occupancy was calculated by following equation: Occupancy $(\%)=\left(\mathrm{K}_{\mathrm{i} \_ \text {baseline }}-\mathrm{K}_{\mathrm{i} \_ \text {pretreatment }}\right)$ / $\mathrm{K}_{\mathrm{i} \_ \text {baseline }} \times 100$, as $\mathrm{K}_{\mathrm{i} \_ \text {baseline }}$ is $\mathrm{K}_{\mathrm{i}}$ at baseline condition and $\mathrm{K}_{\mathrm{i} \_ \text {pretreatment }}$ is $\mathrm{K}_{\mathrm{i}}$ at pretreatment condition. Occupancy using Patlak slope was also calculated. The average occupancy by all ROls was used for further evaluation.

The relationship between average plasma concentration $\left(\mathrm{C}_{\text {ave }}\right)$ of -1 and 30 min of PF-06807893 (active metabolite) and occupancy using Patlak slope was estimated by an $\mathrm{E}_{\max }$ model with the following equation: Occupancy $(\%)=C /\left(E_{50}+C\right) \times E_{m a x}$ as $C$ is the plasma concentration of PF-06807893, $\mathrm{EC}_{50}$ is the plasma concentration required to achieve $50 \%$ of the maximum occupancy, and $\mathrm{E}_{\max }$ is maximum occupancy. In this analysis, $\mathrm{E}_{\max }$ was set as $100 \%$.

\section{Whole-body PET measurements}

Whole-body PET measurements were made in two cynomolgus monkeys (two females, body weight 5350 and $5600 \mathrm{~g}$ ). Anesthesia was administered by intramuscular injection of ketamine hydrochloride (approximately $10 \mathrm{mg} / \mathrm{kg}$ ) at AFL and maintained by intravenous infusion of ketamine $(4 \mathrm{mg} / \mathrm{kg} / \mathrm{h}$ ) and xylazine $(0.4 \mathrm{mg} / \mathrm{kg} / \mathrm{h})$. The body of the NHP was immobilized using a vacuum pad. Body temperature was maintained by a Bair Hugger model 505 and monitored by an esophageal thermometer. Heart rate, blood pressure, and oxygen saturation were continuously monitored throughout the experiments. Fluid balance was maintained by continuous infusion of saline.

Whole-body PET scans were conducted using a GE Discovery PET/CT 710 (GE healthcare, Waukesha, WI, USA). One low-dose CT scan was performed before intravenous administration of [ $\left.{ }^{11} \mathrm{C}\right] \mathrm{PF}-06809247$ for attenuation correction. Then four series of PET acquisitions, each covering four axial fields of view 
(AFOV), were conducted. The four PET series consisted of two $20 \mathrm{~s} \times 4$ AFOV scans, three $40 \mathrm{~s} \times 4$ AFOV scans, four $80 \mathrm{~s} \times 4$ AFOV scans, and six $160 \mathrm{~s} \times 4$ AFOV scans respectively. PET images were reconstructed with a 3D ordered-subset expectation maximization (OSEM) algorithm with three iterations and eighteen subsets, including the time of flight information (VUE Point FX) and the point spread function correction (Sharp IR). A 2D Gaussian filter with $5.5 \mathrm{~mm}$ cut-off was used. The time for the bed to return to the original position was approximately $20 \mathrm{~s}$, and the total duration of the whole-body scan was $100 \mathrm{~min}$.

\section{Image analysis of the whole-body PET}

Regions of interest (ROIs) were drawn on the brain, heart, liver, kidney, lung, stomach, spleen, bone (lumbar vertebrae), gall bladder, urinary bladder and small intestine with the help of the CT images for anatomic landmarks. Radioactivity concentration in each PET scan was decay-corrected to the time of injection. Time activity curve was expressed as percentage of the injected dose (\%ID) calculated as follows: radioactivity $(\mathrm{Bq} / \mathrm{cc}) \times \mathrm{ROI}$ volume $(\mathrm{cc}) /$ injected dose $(\mathrm{Bq}) \times 100$.

\section{Radiation dose estimation}

Estimates of the absorbed radiation dose for humans was calculated with OLINDA/EXM 1.1 (Organ Level INternal Dose Assessment code) software, using the adult male (70 kg) reference model [15]. The fractional uptake in NHP organs was assumed to be equal to the uptake in human organs.

\section{Results}

\section{Brain PET}

The injected radioactivity $(n=20)$ of $\left[{ }^{11} \mathrm{C}\right] \mathrm{PF}-06809247$ was $146 \pm 10$ (mean \pm SD) (range; $\left.120-162\right)$ MBq. The molar radioactivity at the time of injection was $1510 \pm 963(392-4388) \mathrm{GBq} / \mu \mathrm{mol}$, and the injected mass was $0.06 \pm 0.04(0.01-0.15) \mu \mathrm{g}$. Brain uptake was clearly decreased after pretreatment of PF06818883 (NHP4; 0.42 mg/kg, Fig. 1). TACs for several brain regions demonstrated decreased radioactivity, which corresponded to PET images (NHP4; 0.42 mg/kg, Figs. 2A and 2B, Supplemental Fig. 1).

All radiometabolites showed shorter retention times than the parent (Fig. 3). The percent values of plasma parent fraction became less than $10 \%$ after $30 \mathrm{~min}$. The percent values of plasma protein binding were $86.1 \pm 2.8 \%$.

$\mathrm{K}_{\mathrm{i}}$ by $2 \mathrm{TC}$ and Patlak slope were well correlated (Table 2 and Fig. 4). The occupancy range was calculated as $22.8-94.1 \%$ and $25.4-100.5 \%$ by $2 \mathrm{TC}_{\mathrm{i}}$ and Patlak slope, respectively (Table 1 ). The plasma concentration of PF-06807893 was $0.7-370.0 \mathrm{ng} / \mathrm{mL}$. One plasma concentration (dose of 0.01 $\mathrm{mg} / \mathrm{kg}$ for NHP5) showed below lower limit of detection. The pro-drug PF-06818883 was not detected during the PET measurement in most cases (data no shown). $\mathrm{EC}_{50}$ was estimated to be $1.3 \mathrm{ng} / \mathrm{mL}$ (Fig. 5). 
Table 2

Kinetic parameters and $\mathrm{K}_{\mathrm{i}}$ by $2 \mathrm{TC}$ and Patlak slope

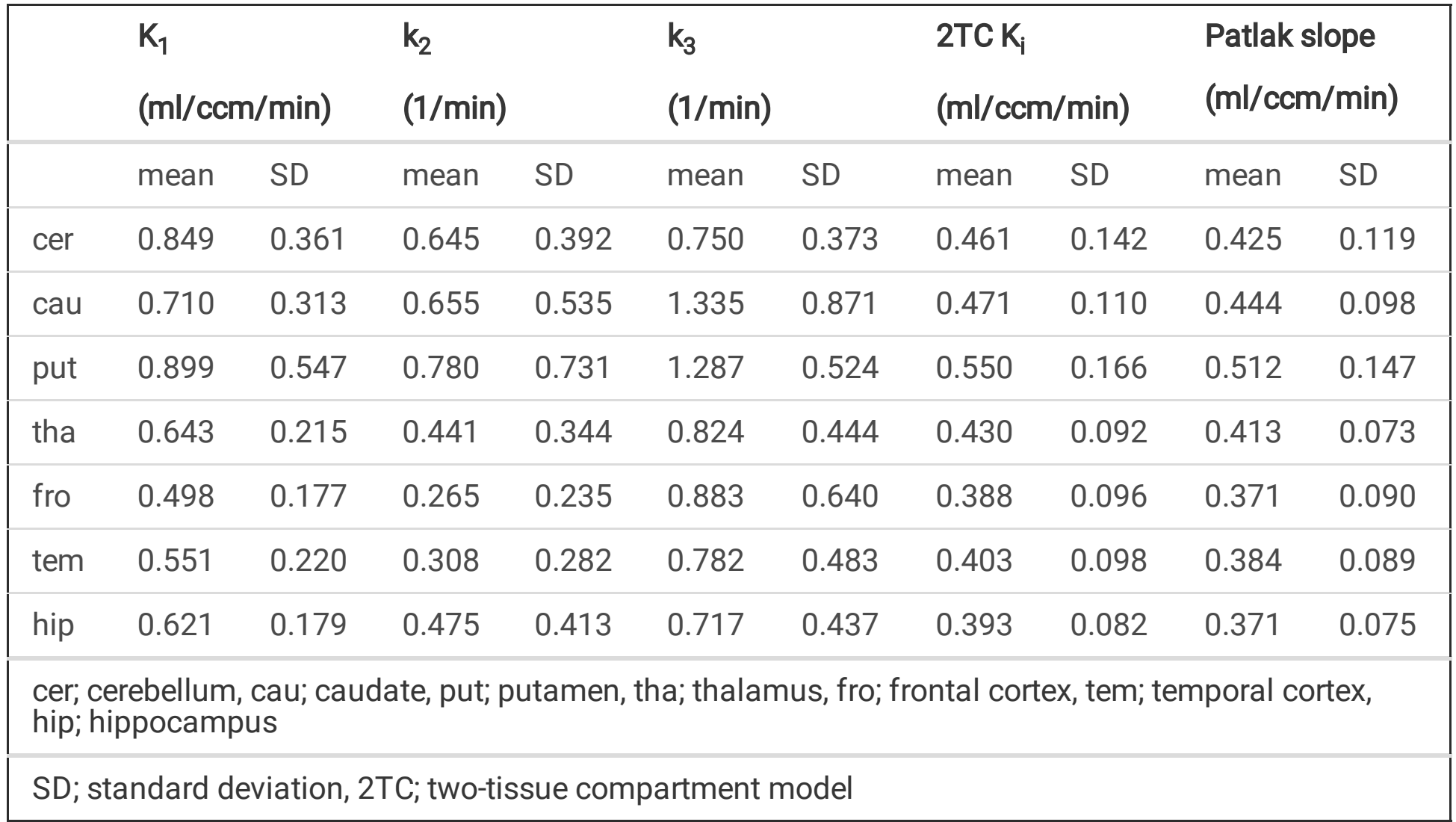

\section{Whole body PET}

The injected radioactivity of $\left[{ }^{11} \mathrm{C}\right] \mathrm{PF}-06809247$ was 272 and $302 \mathrm{MBq}$ for the two measurements, respectively. The molar radioactivity at the time of injection was 186 and $494 \mathrm{GBq} / \mu \mathrm{mol}$, and the injected mass was 0.6 and $0.3 \mu \mathrm{g}$ for the two measurements, respectively. High uptakes were observed in the liver, small intestine, kidney, and brain (Figs. 6, 7A and 7B). The effective dose is $4.3 \mu \mathrm{Sv} / \mathrm{MBq}$ (Table 3). 
Table 3

The radiation dose estimates of $\left[{ }^{11} \mathrm{C}\right] \mathrm{PF}-06809247$

\begin{tabular}{|ll|}
\hline Target Organ & ( $\mu$ Sv/MBq) \\
\hline Adrenals & 3.5 \\
\hline Brain & 6.9 \\
\hline Breasts & 1.7 \\
\hline Gallbladder Wall & 4.3 \\
\hline LLI Wall & 2.8 \\
\hline Small Intestine & 17.2 \\
\hline Stomach Wall & 2.7 \\
\hline ULI Wall & 7.4 \\
\hline Heart Wall & 10.8 \\
\hline Kidneys & 39.7 \\
\hline Liver & 12.6 \\
\hline Lungs & 3.8 \\
\hline Muscle & 2.0 \\
\hline Ovaries & 3.3 \\
\hline Pancreas & 3.5 \\
\hline Red Marrow & 2.2 \\
\hline Osteogenic Cells & 2.7 \\
\hline Skin & 1.5 \\
\hline Spleen & 10.3 \\
\hline Testes & 1.6 \\
\hline Thymus & 2.0 \\
\hline Thyroid & \\
\hline Urinary Bladder Wall & 5.3 \\
\hline Uterus & \\
\hline Total Body & \\
\hline Effective Dose & \\
\hline
\end{tabular}

Page 10/22 


\section{Discussion}

In this study, we present a novel MAGL PET radioligand, [ $\left.{ }^{11} \mathrm{C}\right] \mathrm{PF}-06809247$ which showed high uptake in the NHP brain and clear blocking effect by a selective MAGL inhibitor. The uptake of $\left[{ }^{11} \mathrm{C}\right] \mathrm{PF}-06809247$ was relativley uniform thoughout the brain with slightly higher uptake in the celleberum and putamen and lower uptake in the cerebral cortical regions. Brain uptake was clearly decreased in all brain regions following pretreatment with a high dose of a previously described selective MAGL inhibitor. The relationship between plasma concentration and occupancy was observed in a dose-dependent manner. This suggests that $\left[{ }^{11} \mathrm{C}\right] \mathrm{PF}-06809247$ is sensitive enough to detect a range of MAGL inhibition and demonstrates the ammenability of $\left[{ }^{11} \mathrm{C}\right] \mathrm{PF}-06809247$ for assessing MAGL occupancy in vivo.

The radio-HPLC data showed that $\left[{ }^{11} \mathrm{C}\right] \mathrm{PF}-06809247$ was rapidly metabolized to less than $10 \%$ of total radioactivity in plasma by $30 \mathrm{~min}$. The major radiometabolite could be separated by radio-HPLC and had a retention time that was short $(1.9 \mathrm{~min})$ compared to parent fraction $(3.1 \mathrm{~min})$, indicating a low probability of brain penetration by the radiometabolite.

The 2TC model with 3-parameters using arterial input function could describe the TACs of $\left[{ }^{11} \mathrm{C}\right] \mathrm{PF}-$ 06809247. A 2TC model with 4-parameters did not descirbe the data well (data not shown). Also, the ratio of brain uptake to metabolite-corrected plasma showed continuously increasing at the duration of quantification (supplement Fig. 2). These imply that $\left[{ }^{11} \mathrm{C}\right] \mathrm{PF}-06809247$ has irreversible binding properties and is indeed consistent with prior pharmacological study [8]. The Patlak slope was well correlated with $\mathrm{K}_{\mathrm{i}}$ by $2 \mathrm{TC}$ model estimation although a slight underestimation (around $7 \%$ ) was observed. This suggests that graphical analysis would be useful for further evaluations such as parametric image analysis.

The whole-body measurement showed highest accumulation in the liver and small intestine, and relatively low accumulation in the urinary bladder. Notably, the uptake in the brain was also high (7\% ID at peak). The effective dose of $\left[{ }^{11} \mathrm{C}\right] \mathrm{PF}-06809247$ was $4.3 \mu \mathrm{Sv} / \mathrm{MBq}$, which was similar to the median value $(4.7 \mu \mathrm{Sv} / \mathrm{MBq})$ of other carbon-11 PET radioligands [16]. This radiation exposure would allow multiple administrations in a single subject enabling longitudinal and/or baseline blocking studies in human.

Recently, several studies for NHP brain imaging using PET radioligands for MAGL were reported using $\left[{ }^{11} \mathrm{C}\right]$ MAGL-0519 [17], $\left[{ }^{11} \mathrm{C}\right]$ SAR127303 [18], $\left[{ }^{11} \mathrm{C}\right] M A-P B-1$ [19], $\left[{ }^{18} \mathrm{~F}\right] \mathrm{T}-401$ [20], and [ $\left.{ }^{18} \mathrm{~F}\right] \mathrm{PF}-06795071$ [1]. In addition, a report highlighting the opportunities and challenges of PET imaging of the endocannabinoid system was recently published [21]. Compared to these PET radioligands, [ $\left.{ }^{11} \mathrm{C}\right] \mathrm{PF}-06809247$ showed similar or higher brain uptake (4 SUV at peak) with clear blocking effect by a defined MAGL inhibitor. This data suggests that $\left[{ }^{11} \mathrm{C}\right] \mathrm{PF}-06809247$ would be a useful PET radioligand for human studies.

One potential limitation of this study is in the use of $\mathrm{K}_{\mathrm{i}}$ as the primary outcome measure for determining target occupancy. Theoretically, the rate constant $\mathrm{k}_{3}$ would be more appropriate, under the conventional assumption that its value is proportional to the available enzyme concentration. However, as shown in Table 2 , the estimated $k_{3}$ values were highly variable, so this outcome measure was not appropriate for 
occupancy estimates. This behavior is quite common for irreversibly bound PET radioligands, especially under baseline conditions where enzyme availability is high. Specifically, if baseline $k_{3}$ is much higher than $\mathrm{k}_{2}$ (the clearance rate from tissue), radioligand uptake is flow limited [22]. Thus, using $\mathrm{K}_{\mathrm{i}}$ as the outcome measure will likely lead to underestimation of baseline enzyme availability. Under blocking conditions, $k_{3}$ is reduced and enzyme availability becomes the rate limiting step, in which case $K_{i}$ will be more reflective of remaining enzyme availability, i.e., no longer flow limited. It is thus possible that occupancy was underestimated (since baseline $\mathrm{K}_{\mathrm{i}}$ is underestimated), in which case the $\mathrm{EC}_{50}$ may be overestimated.

\section{Conclusions}

The NHP brain occupancy measured with $\left[{ }^{11} \mathrm{C}\right] \mathrm{PF}-06809247$ showed concentration dependency following dosing of a selective MAGL inhibitor. This data suggests that $\left[{ }^{11} \mathrm{C}\right] \mathrm{PF}-06809247$ can accurately estimate the MAGL activity. The effective dose of $\left[{ }^{11} \mathrm{C}\right] \mathrm{PF}-06809247$ was similar to other reported carbon-11 PET radioligands. Therefore, $\left[{ }^{11} \mathrm{C}\right] \mathrm{PF}-06809247$ is a promising PET ligand for estimating MAGL activity and occupancy in human brain.

\section{Declarations}

Ethics approval: All studies were approved by the Animal Ethics Committee of the Swedish Animal Welfare Agency (N185/14) and performed according to "Guidelines for planning, conducting and documenting experimental research" (Dnr 4820/06-600) of Karolinska Institutet.

Competing interests: Kevin P. Maresca, Lei Zhang, Edmund J. Keliher, Christopher R. Butler, Justin R. Piro, Tarek A. Samad, Deborah Smith, Deane Nason, Steve O'Neil, Patrick Trapa, Kari R. Fonseca, John Litchfield, and Timothy McCarthy were employees of Pfizer Inc. when the study was conducted. Other authors have no conflict of interest.

Funding: This work was sponsored by Pfizer Inc..

\section{Authors' contributions:}

Contributing to conception and design: Ryosuke Arakawa, Akihiro Takano, Sangram Nag, Zhisheng Jia, Nahid Amini, Kevin P. Maresca, Lei Zhang, Edmund J. Keliher, Christopher R. Butler, Justin R. Piro, Tarek A. Samad, Deane Nason, Steve O’Neil, Patrick Trapa, Kari R. Fonseca, John Litchfield, Timothy McCarthy, Christer Halldin

Acquiring data: Ryosuke Arakawa, Akihiro Takano, Sangram Nag, Zhisheng Jia, Nahid Amini

Analyzing_and interpreting_data: Ryosuke Arakawa, Akihiro Takano, Sangram Nag, Zhisheng Jia, Nahid Amini, Kevin P. Maresca, Edmund J. Keliher, Christopher R. Butler, Justin R. Piro, Tarek A. Samad, Deborah Smith, Patrick Trapa, Kari R. Fonseca, John Litchfield, Richard E. Carson, Christer Halldin 
Acknowledgements: Authors thank all the members of the Karolinska PET group for their assistance in PET experiments, including special thanks to Kia Hultberg-Lundberg and Jonas Ahlgren for excellent technical assistance. Authors would like to thank Dr. Michael Stabin (Vanderbilt University) for helping in calculation of the absorbed radiation dose.

\section{References}

1. Varlow C, Boileau I, Wey HY, Liang SH, Vasdev N. Classics in Neuroimaging: Imaging the Endocannabinoid Pathway with PET. ACS Chem Neurosci. 2020;11:1855-1862.

2. Grimsey NL, Savinainen JR, Attili B, Ahamed M. Regulating membrane lipid levels at the synapse by small-molecule inhibitors of monoacylglycerol lipase: new developments in therapeutic and PET imaging applications. Drug Discov Today. 2020;25:330-343.

3. Terrone G, Pauletti A, Salamone A, et al. Inhibition of monoacylglycerol lipase terminates diazepam-resistant status epilepticus in mice and its effects are potentiated by a ketogenic diet. Epilepsia. 2018;59:79-91.

4. Piro JR, Suidan GL, Quan J, et al. Inhibition of 2-AG hydrolysis differentially regulates blood brain barrier permeability after injury. J Neuroinflammation. 2018;15.

5. Piro JR, Benjamin DI, Duerr JM, et al. A Dysregulated Endocannabinoid-Eicosanoid Network Supports Pathogenesis in a Mouse Model of Alzheimer's Disease. Cell Rep. 2012;1:617-623.

6. Bedse G, Hill MN, Patel S. 2-Arachidonoylglycerol Modulation of Anxiety and Stress Adaptation: From Grass Roots to Novel Therapeutics. Biol Psychiatry. 2020;88:520-530.

7. Gil-Ordóñez A, Martín-Fontecha M, Ortega-Gutiérrez S, López-Rodríguez ML. Monoacylglycerol lipase (MAGL) as a promising therapeutic target. Biochem Pharmacol. 2018;157:18-32.

8. Zhang L, Butler CR, Maresca KP, et al. Identification and Development of an Irreversible Monoacylglycerol Lipase (MAGL) Positron Emission Tomography (PET) Radioligand with High Specificity. J Med Chem. 2019;62:8532-8543.

9. Varrone A, Sjöholm N, Eriksson L, Gulyás B, Halldin C, Farde L. Advancement in PET quantification using 3D-OP-OSEM point spread function reconstruction with the HRRT. Eur J Nucl Med Mol Imaging. 2009;36:1639-1650.

10. Moein MM, Nakao R, Amini N, Abdel-Rehim M, Schou M, Halldin C. Sample preparation techniques for radiometabolite analysis of positron emission tomography radioligands; trends, progress, limitations and future prospects. TrAC - Trends Anal Chem. 2019;110:1-7.

11. Moein MM, Halldin C. Sample preparation techniques for protein binding measurement in radiopharmaceutical approaches: A short review. Talanta. 2020;219. 
12. Butler C, McAllister L, Beck E, et al. 1,1,1-Trifluoro-3-Hydroxypropan-2-YI Carbamate Derivatives and 1,1,1-Trifluoro-4-Hydroxybutan-2-YI Carbamate Derivatives As Magl Inhibitors. Us20170029390. 2017.

13. Innis RB, Cunningham VJ, Delforge J, et al. Consensus nomenclature for in vivo imaging of reversibly binding radioligands. J Cereb Blood Flow Metab. 2007;27:1533-1539.

14. Patlak CS, Blasberg RG, Fenstermacher JD. Graphical evaluation of blood-to-brain transfer constants from multiple-time uptake data. J Cereb Blood Flow Metab. 1983;3:1-7.

15. Stabin MG, Sparks RB, Crowe E. OLINDA/EXM: The second-generation personal computer software for internal dose assessment in nuclear medicine. J Nucl Med. 2005;46:1023-1027.

16. Zanotti-Fregonara P, Innis RB. Suggested pathway to assess radiation safety of 11C-labeled PET tracers for first-in-human studies. Eur J Nucl Med Mol Imaging. 2012;39:544-547.

17. Cheng R, Mori W, Ma L, et al. In Vitro and in Vivo Evaluation of 11 C-Labeled Azetidinecarboxylates for Imaging Monoacylglycerol Lipase by PET Imaging Studies. J Med Chem. 2018;61:2278-2291.

18. Wang L, Mori W, Cheng R, et al. Synthesis and preclinical evaluation of sulfonamidobased [11CCarbonyl]-carbamates and ureas for imaging monoacylglycerol lipase. Theranostics. 2016;6:1145-1159.

19. Ahamed M, Attili B, van Veghel D, et al. Synthesis and preclinical evaluation of [11C]MA-PB-1 for in vivo imaging of brain monoacylglycerol lipase (MAGL). Eur J Med Chem. 2017;136:104-113.

20. Hattori Y, Aoyama K, Maeda J, et al. Design, Synthesis, and Evaluation of (4 R)-1-\{3-[2-(18F)Fluoro4-methylpyridin-3-yl]phenyl\}-4-[4-(1,3-thiazol-2-ylcarbonyl)piperazin-1-yl]pyrrolidin-2-one ([18F] T-401) as a Novel Positron-Emission Tomography Imaging Agent for Monoacylglycerol Lipase. J Med Chem. 2019;62:2362-2375.

21. Hou L, Rong J, Haider A, et al. Positron Emission Tomography Imaging of the Endocannabinoid System: Opportunities and Challenges in Radiotracer Development. J Med Chem. 2021;64:123-149.

22. Koeppe RA, Frey KA, Snyder SE, Meyer P, Kilbourn MR, Kuhl DE. Kinetic modeling of N[11C]methylpiperidin-4-yl propionate: Alternatives for analysis of an irreversible positron emission tomography tracer for measurement of acetylcholinesterase activity in human brain. $J$ Cereb Blood Flow Metab. 1999;19:1150-1163.

\section{Figures}




\section{Fig1}

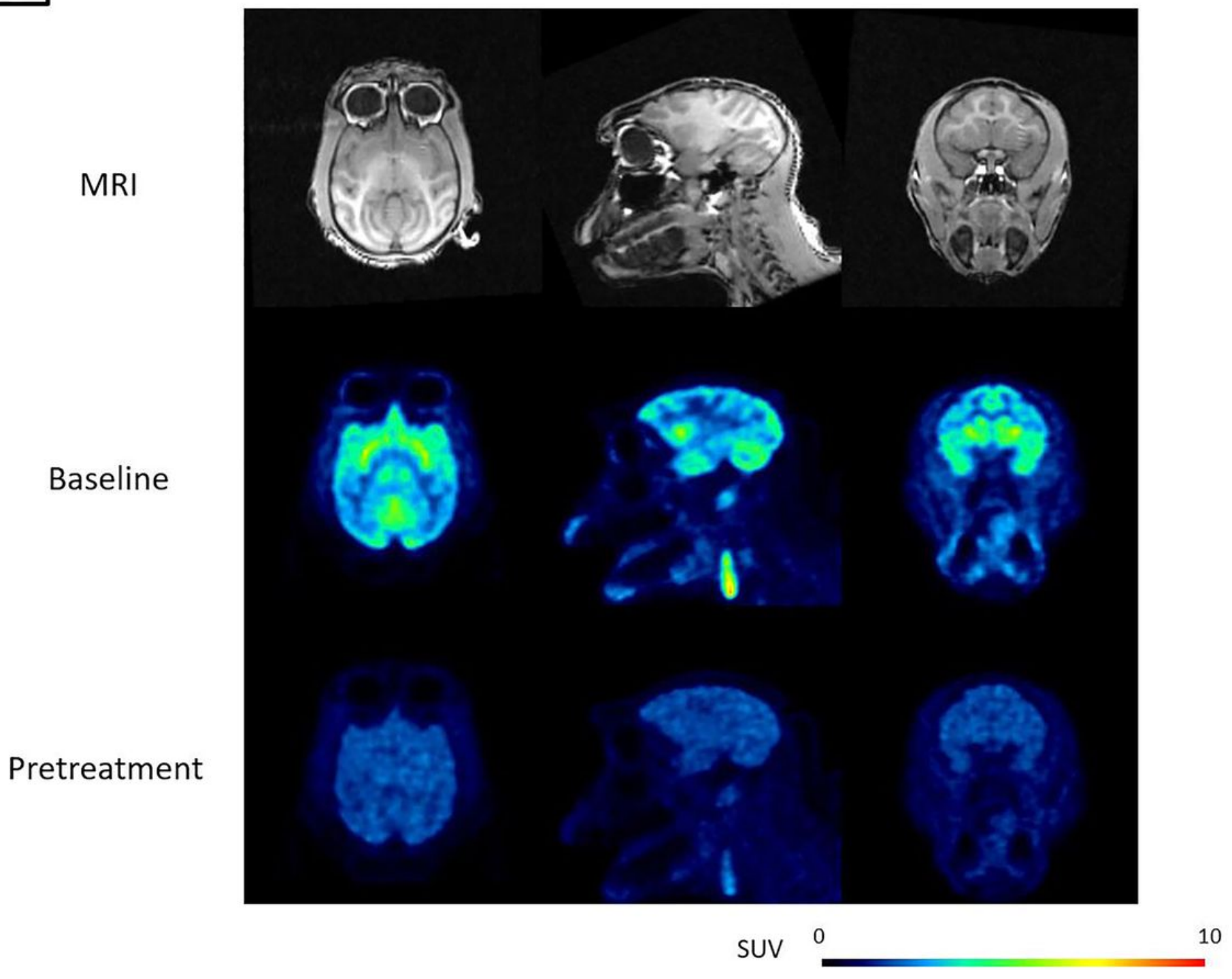

\section{Figure 1}

Representative MRI and PET summation images of [11C]PF-06809247 at baseline and following pretreatment with a selective MAGL inhibitor (NHP4; $0.42 \mathrm{mg} / \mathrm{kg}$ ) 

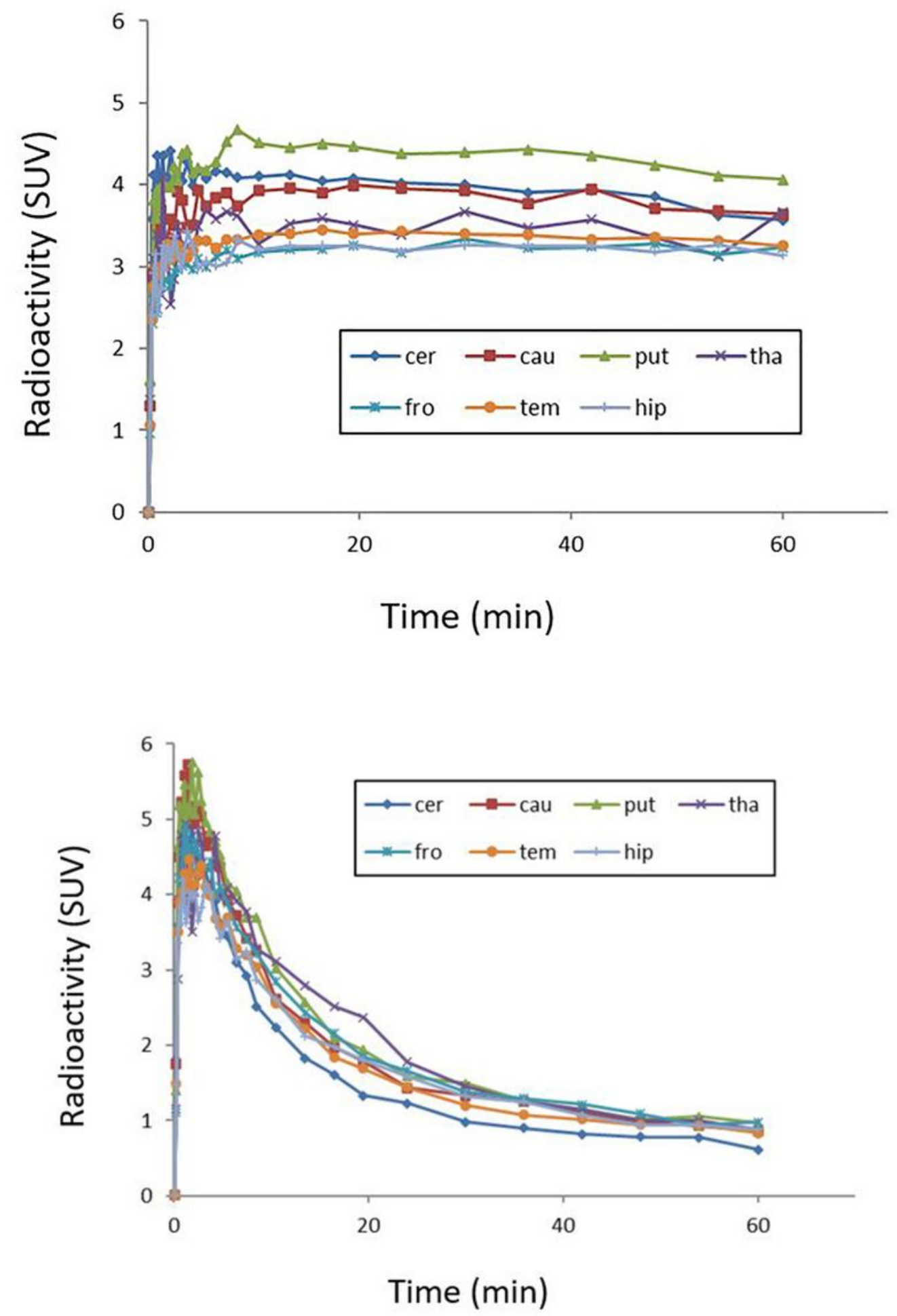

Figure 2

Representative time activity curves of [11C]PF-06809247 in the NHP brain at (a) baseline and (b) following pretreatment with a selective MAGL inhibitor (NHP4; $0.42 \mathrm{mg} / \mathrm{kg}$ ) cer; cerebellum, cau; caudate, put; putamen, tha; thalamus, fro; frontal cortex, tem; temporal cortex, hip; hippocampus 

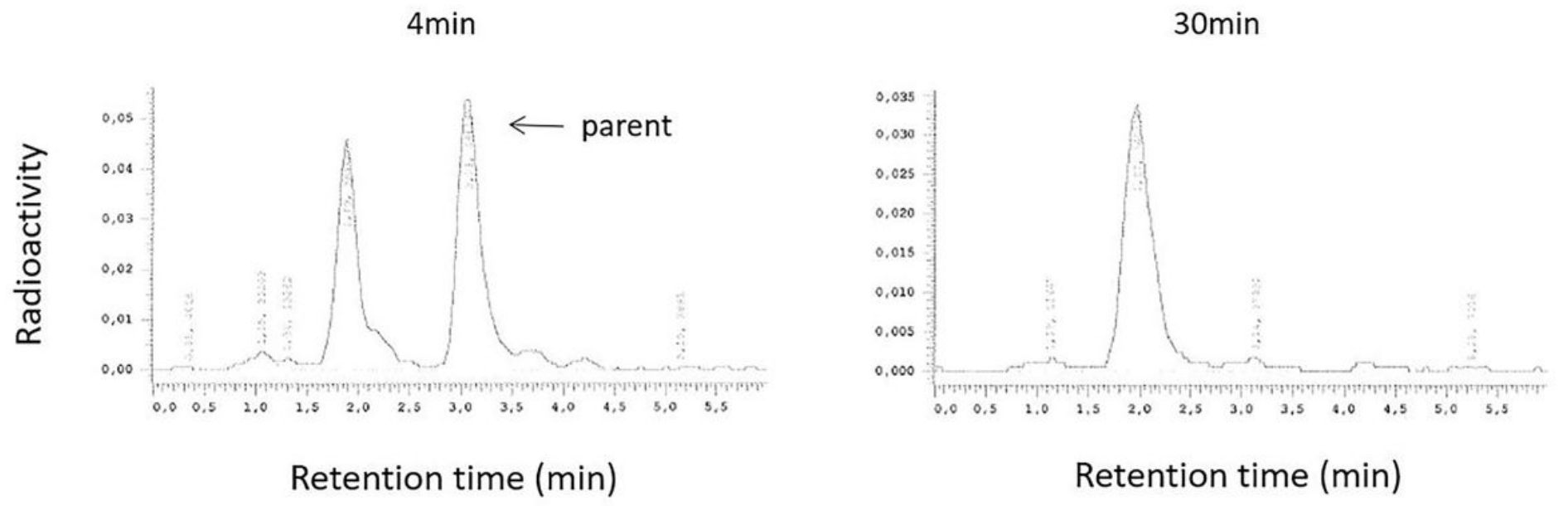

Figure 3

Radio-HPLC of baseline condition at 4- and 30-minutes post administration of [11C]PF-06809247 


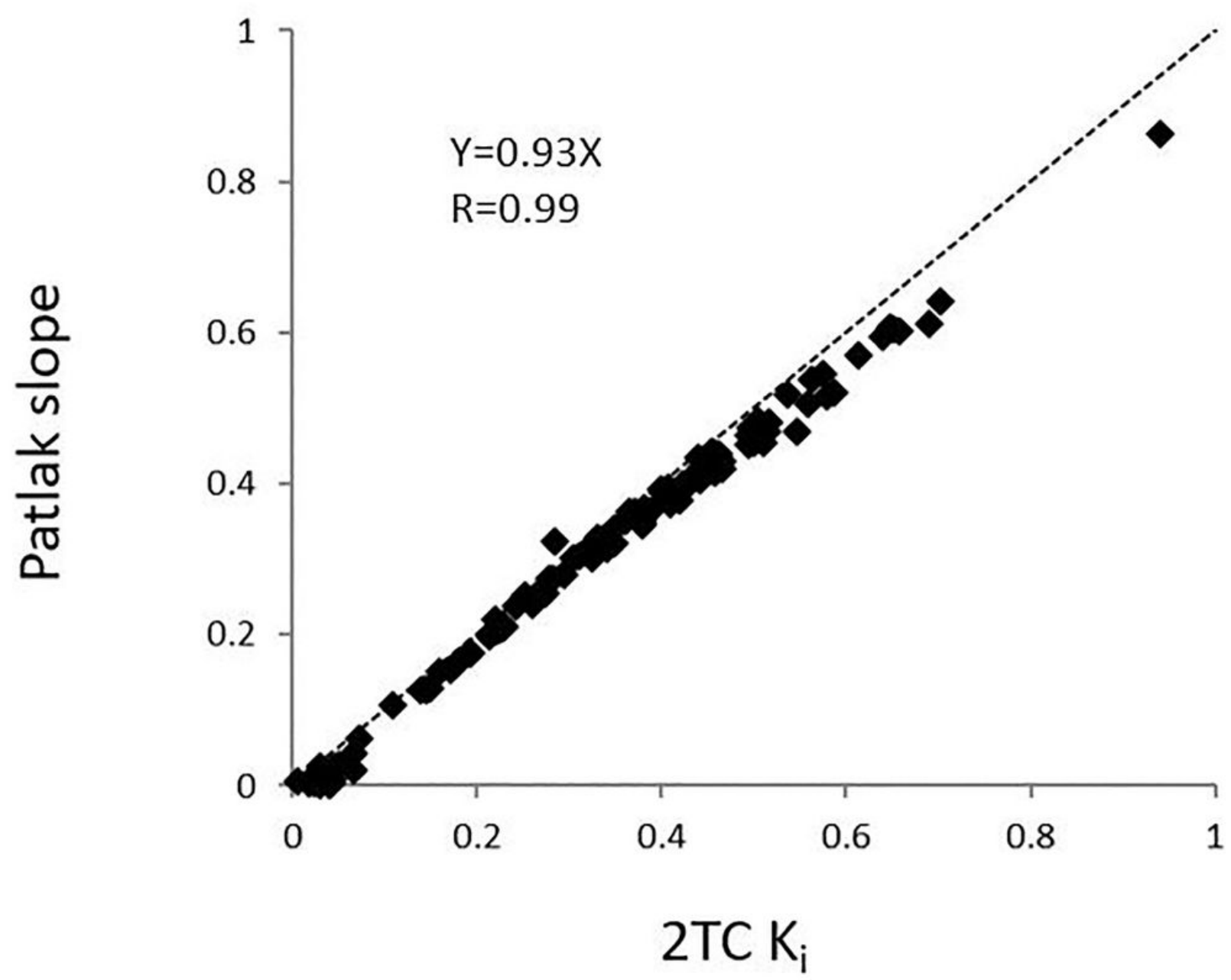

Figure 4

Correlation of Ki measured by 2TC model and Patlak slope 


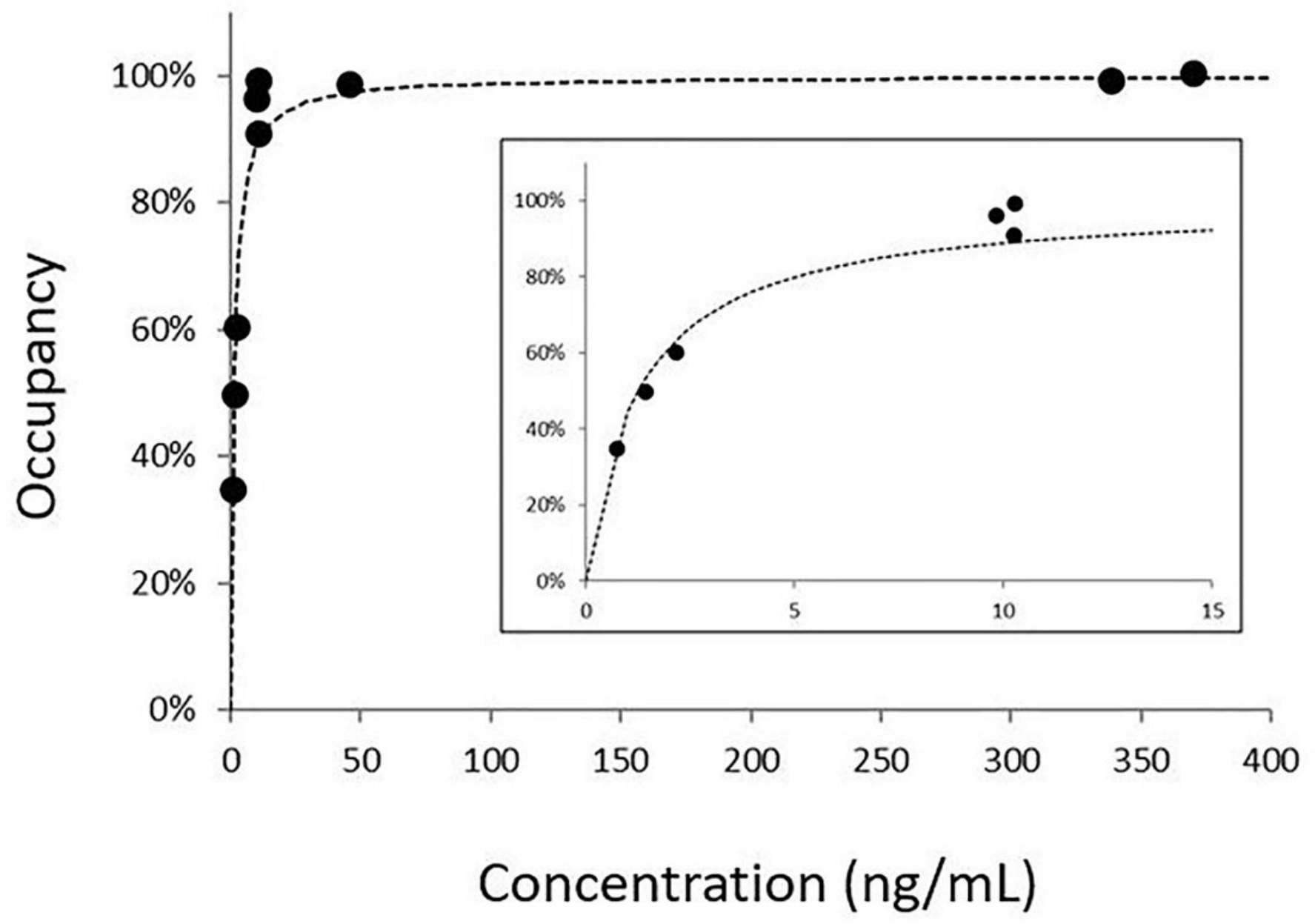

Figure 5

Relationship between plasma concentration of PF-06807893 and MAGL occupancy 


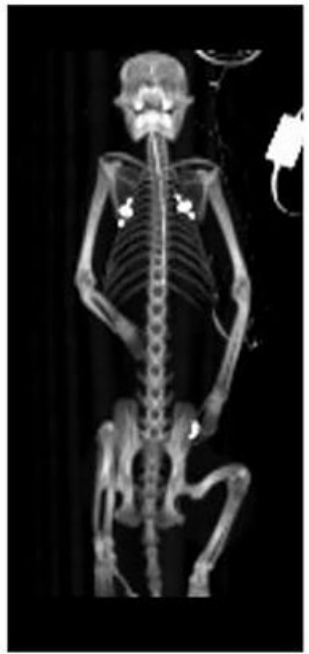

CT

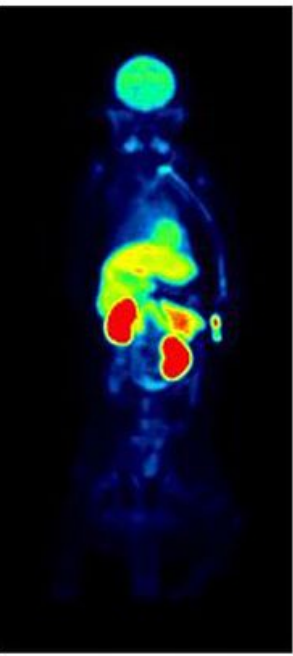

$2 \min$

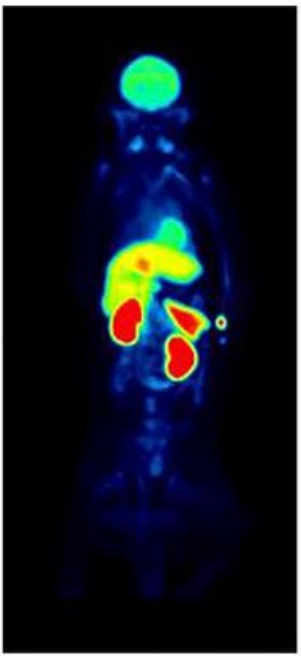

$11 \mathrm{~min}$

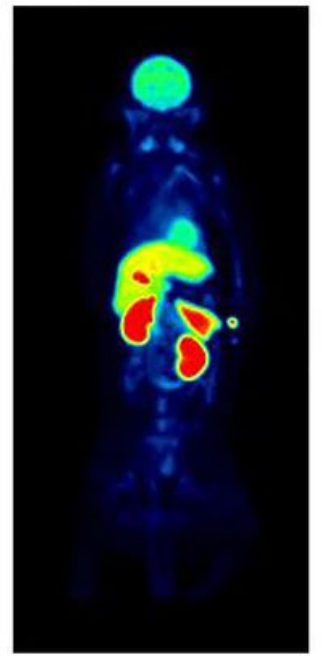

$21 \mathrm{~min}$

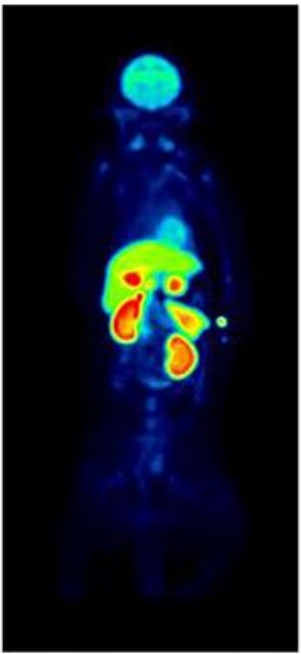

$52 \mathrm{~min}$

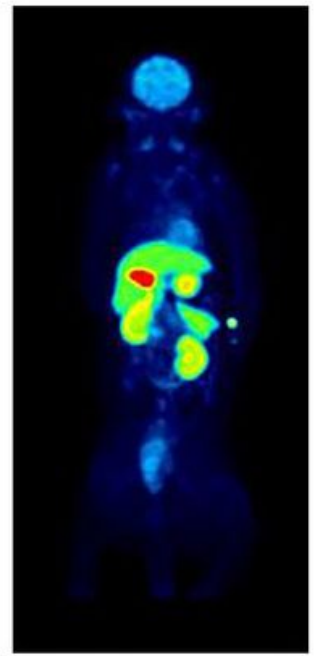

$96 \min$

SUV 0

Figure 6

Representative whole-body PET images of [11C]PF-06809247 

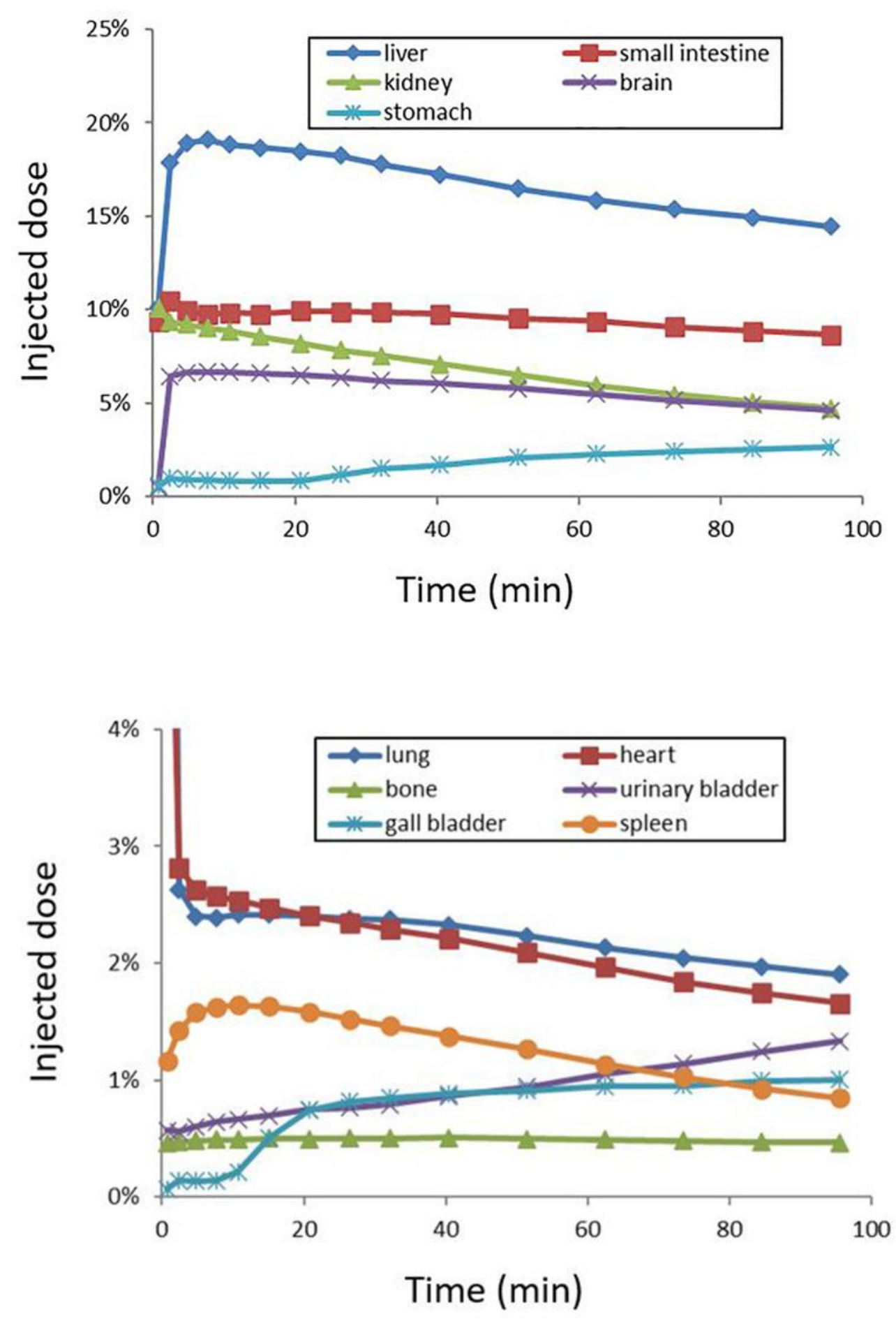

Figure 7

Representative time activity curves of [11C]PF-06809247 in (a) high accumulation organs and (b) low accumulation organs

\section{Supplementary Files}


This is a list of supplementary files associated with this preprint. Click to download.

- ArakawaMAGLTOEJNMMIressup.docx 